\title{
Mobile Learning Application Development Fostering High Order Thinking Skills on Physics Learning
}

\author{
Dwi Sulisworo ${ }^{1}$ \\ ${ }^{1}$ Ahmad Dahlan University, Indonesia
}

\begin{abstract}
Educators and students are already quite mature and ready to take the advantage of mobile technology from both social and technology aspect. Various studies have been conducted in the use of technology to improve learning performance. Higher order thinking skills or HOTS is an important thing that needs to be possessed by the students to understand a specific knowledge. The integration between the positive opportunities in the use of mobile technology and learning strategies based on the concept of HOTS is the basic idea of this research to develop a mobile learning application. This research is the development of mobile learning application with android platform that incorporate strategies for developing higher order thinking skills. In this study, the learning strategy applied in the management of the activities leading to the higher order thinking skills is $4 R$ (read, reflection, recite, and review) as a modification of the PQ4R strategy (preview, question, read, reflection, recite, and review).
\end{abstract}

Keywords: higher order thinking, learning strategy, mobile application, mobile learning

\section{Introduction}

In recent years there has been a significant change in the awareness of teachers to utilize ICT in learning, especially in mobile learning [1][2]. This phenomenon is part of the implication of the rapid development of wireless technology and mobile learning in recent years. It makes educators realize that digital technology presents opportunities for different forms of learning; including the relationship between teachers and students, teachers and the teachers, students and students, and students with teaching materials or competence [3][4]. Provision of learning content by using mobile technology has been developed by teachers for a variety of subject matter and also for the development of various learning strategies. In addition, reforms in education have provided rich opportunities of mobile learning usage to forming a more flexible learning environment that accommodate differences in students [2][5].

In general, the shortcomings of mobile applications for learning available in the market is not yet using application for specific learning strategies that focus on increasing higher order thinking skills [6][7][8]. Thus, the learning is presented through material presentation, exercises and evaluation. In fact, various studies indicate that the higher order thinking skills intensifying on the interaction among the students, competence, and teaching materials can improve learning performance significantly. This research is a development research that specifically incorporates a variety of learning strategies that lead to an increase of higher order thinking skills. The product of this research is the application of mobile learning with android platform developed using ExeLearning. The instructional material used here is physics matters in sub material of Heat and Temperature for junior high school students. 


\section{Literature Review}

\subsection{Mobile Learning}

Mobile learning (m-learning) is part of e-learning that provides wider opportunities in mobile and more capabilities for student learning. Thus m-learning can be defined differently by e-learning related to the mobility of students as learners. This learning can be done anywhere by the students whenever they have available mobile technology. This learning mode is growing rapidly at recent year. It can be specified as techno-centric, focus on e-learning, formal education components, and student-centred learning. Today, the emphasis of technology in schools is to ensure an effective learning with new opportunities and drive better learning performance [9][10].

Mobile technology used on learning has significant impact on learning environment shifting [11][12]. Many educational institutions have provided some alternative models of learning activities to learners. The goal is that the learners can flexibly manage learning activities in accordance with their available time and daily activities [13][14]. Mobile learning facilitates interaction between learners with the subject matter, between learners and teachers or even between fellow learners by sharing information or opinions about various matters that relates the lessons or self-development needs, regarding the learners' learning [15][16][17][18].

\subsection{High Order Thinking Skills}

Higher order thinking skills or HOTS, is a concept used in the educational reform in various institutions based on learning taxonomy such as Bloom's Taxonomy. The basic idea of HOTS concept is that some types of learning for particular knowledge requires higher cognitive processing than other knowledge [19][20]. In Bloom's taxonomy, skills such as analysis, evaluation, synthesis and creation are considered to have a higher level than the ability to memorize facts and concepts. Thus it will require particular strategies or different learning methods. This Higher order thinking involves a high degree of skill to decide a complex matter requiring critical thinking skills and problem solving [20][21]. Higher order thinking is more difficult to teach, but it is more beneficial for the future because it will always be used to manage new situations [2][4].

Research on how people learn indicates that active learning will be more effective than just a face-to-face lecture [5][22]. There are many strategies that can be used in higher order thinking skills enhancement. Some of the principles in learning that encourage the increase of HOTS of are to teach the concept of concept, tell and show, moving from concrete to abstract and back, teach steps to learning concepts, go from basic to sophisticated, connect concepts, teach inference [8][21][23].

\subsection{Read, Reflect, Recite and Review}

PQ4R learning model (Preview, Question, Read, Reflection, Recite, and Review) is part of an innovative learning models orienting to constructivism theory. Constructivism learning theory allows students the opportunity to find themselves and to transform complex information, to discover new information with the old rules and to revise these rules when they are no longer relevant. The PQ4R learning steps are as follows:

- Preview: giving students the opportunity to read the text quickly to find the main idea of learning.

- Question: asking students to create their own questions as the result of quick reading.

- Read: giving students the opportunity to read actively and depth, while giving feedback.

- Reflect: giving students the problems and solve the problems with the information provided by the teacher and the knowledge of reading.

- Recite: asking students to look back in the records or extracts made previously from reading.

- Review: reading back the learning sources and strengthen their understanding of the passage.

Considering the degree of suitability of this application on mobile learning, the researcher did not do a Preview and Question steps. This is because the students cannot be restricted doing activity in the mobile device, and they tend to be more flexible in using the learning resources in accordance with their level of needs. Activity in the first application here is to provide students reading materials for reading. So this strategy becomes 4R, i.e. 
Read, Reflect, Recite and Review. Therefore, there is a difference between this learning models compared to the PQ4R.

\section{Methods}

This research is product development research using PMBOK methodology. The Project Management Institute (PMI®) published the PMBOK® guide in 2000 [24]. The product development processes are as follows:

- Initiating processes. It includes measurement of needs, literature study, limited research, collecting information (literature review, class observation), identification of problems found in learning process, and summarizes the issues and considerations in terms of value.

- Planning processes. It includes the abilities required in the conduct of research, the formulation of the research objectives to be achieved with the study, design or research steps, and the possibility of testing in a limited scope.

- Executing processes. It covers the development of learning materials, learning process and evaluation instruments.

- Controlling processes. Limited test is carried out on a small scale about 25 respondents. The respondents' response is obtained through a questionnaire. The product is revised based on this questionnaire result until fit to the requirements.

- Closing processes: formalizing acceptance of the phase and bringing the product to an orderly end.

\section{Result and Discussion}

\subsection{The structure of application features}

After going through improvements in display aspect and display chronology of the menu for 3 times, then the structure of the resulting application can be seen in the diagram of Figure 1 below.

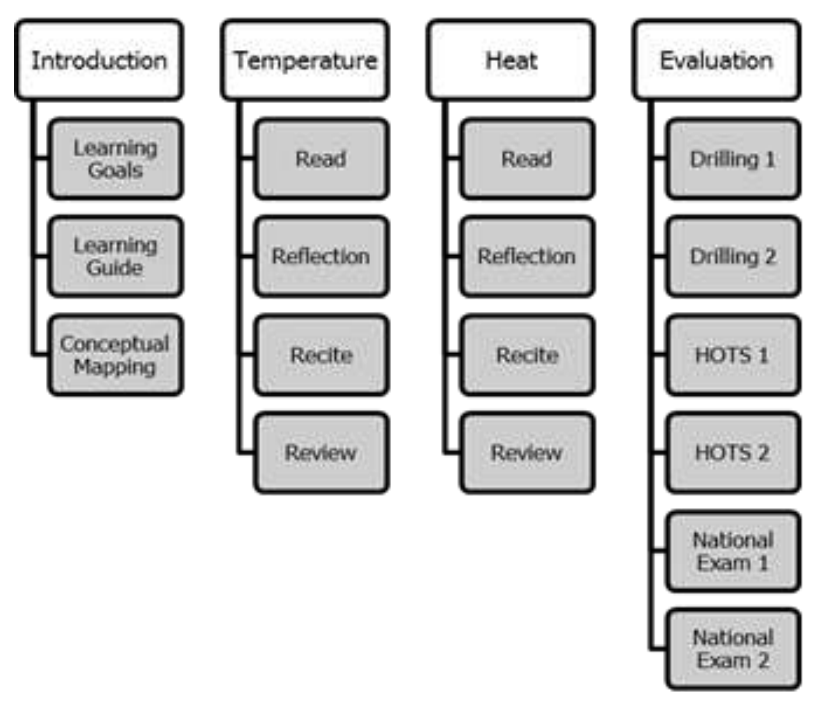

Fig. 1: Feature structure of the application. 
Some of the screenshots of this application are shown by figure 2 .

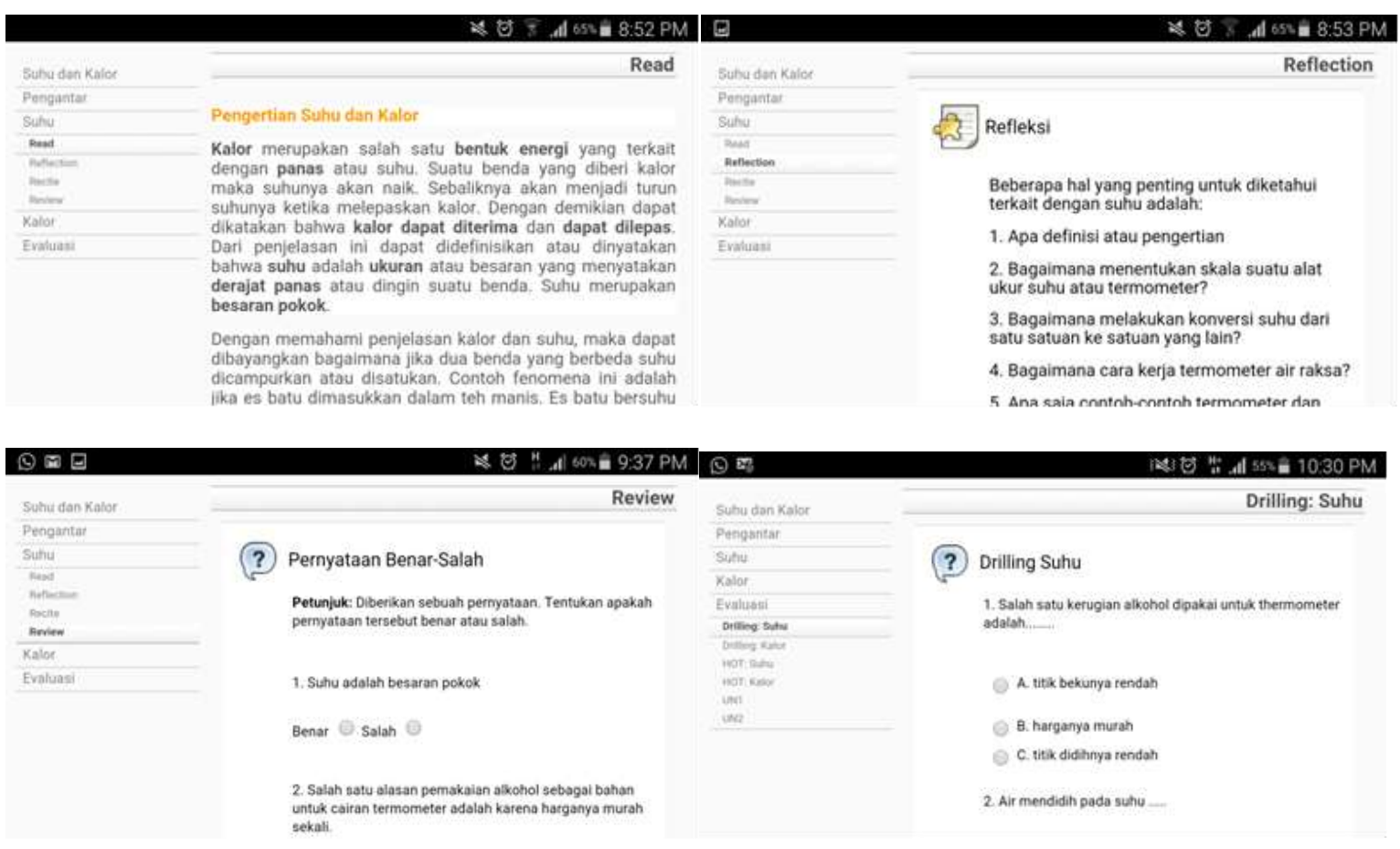

Fig. 2: Screenshots of some activities.

\subsection{Four R's Activities}

Read

In this menu, the reading material is given to students for learning before entering the next stage. The readings are written in simple language and communicative so that students are more motivated to read. The material content is written in connection with phenomena they encountered in everyday in order to obtain more concrete picture of the material being studied. The important concepts in the readings are made with bold font to be more easily captured by the students.

\section{Reflection}

Based on the literature that has been read, the students are expected to make reflection to internalize the insights gained. The menu gives two things: reflective questions need to be answered by the students to determine if the material being read has been sufficiently understood. If not, then it needs to re-read the material. In this section there is an order that the students must remember the material being read to answer some reflective questions. For example, question reflection in the material temperature is "what is the definition or meaning of temperature?". Besides, it also provided a menu to answer the reflective questions to ensure that their understanding has been correct. This reflection stage also provided answers menu that can be opened or closed by pressing certain buttons. This is to allow students to be able to test themselves concerning their understanding toward the material.

\section{Recite}

On Recite menu, students will be given opportunity to apply their understanding to solve some simple cases. The students are expected to solve the problems with the way of independent thinking. In doing so, the answer to the problems has also been given as a reference when students deal with the problems to ensure whether the results of the answers are correct or not. Students can discuss offline or through other channels with other students to solve this problem. 


\section{Review}

In the review menu, students are given two kinds of exercises, namely easy level and difficult level. The Easy is administered in the form of true or false statement, which consists of 10 questions. The focus at this level is to remember and repeat the basic concepts of the material. Meanwhile, the 'Difficult Level' is given in the form of more complex problems. There are five types of complex problems provided. The problems provided there is a correlation between the existing situations with the real situation, so that students can understand the abstract problems (mathematical models) as the illustration of the concrete problems (the real situation). There are three possible answers to each problem. In addition, the existence of the difficult level is also intended to enable students to independently measure their ability at the level it deserves. If the understanding obtained is not sufficient, students are advised to return to the previous menu.

\subsection{Evaluation}

Evaluation is divided into three categories, namely: drilling, higher order of thinking (HOT), and the exercise of national examinations. Evaluation in drilling contains simple questions that are repeated continuously to obtain a better process of concept internalization. In this section there are 10 multiple choice questions with 3 possible answers. Furthermore, evaluation of the higher order thinking skills or HOTS is presented in the form of a reflection to a case study. Students are first asked to think about the steps to the problem solving process.

This menu also provides an explanation of suitable procedures, by pressing the button 'click here'. This explanation can be closed again by pressing the 'hide' button. This facility is useful to know whether the students have taken correct procedures or not, and also to find out the problems solving stages.

\section{Conclusion}

This article focuses on developing the learning application by combining the strategy to improve higher order thinking skills and mobile technology. This application can not directly enhance student motivation, but the teacher role to engage student is very important. This mobile application has been developed with simple features but adequate for good learning at certain subject of physics at high school level. Some features of the interface are default taken from the ExeLearning tool. Application can be downloaded at https://drive.google.com/open?id=0BwZPbWzZOQfrb2NpR3dQb3JSNGc.

\section{Acknowledgements}

This research was funded by Research and Development Agency of Ahmad Dahlan University under Competitive Research Grant for year 2015/ 2016.

\section{References}

[1] Alqahtani, M., \& Mohammad, H. (2015). Mobile Applications' Impact on Student Performance and Satisfaction. TOJET: The Turkish Online Journal of Educational Technology, Vol. 14 Issue 4, 102-112.

[2] Thinley, P., Reye, J., \& Geva, S. (2014). Tablets (iPad) for M-Learning in the Context of Social Constructivism to Institute an Effective Learning Environment. International Journal of Interactive Mobile Technology; Vol. 8, Issue 1, $16-20$.

[3] Arnab, S., Lim, T., Carvalho, M. B., Bellotti, F., Freitas, S., Louchart, S., ... \& De Gloria, A. (2015). Mapping learning and game mechanics for serious games analysis. British Journal of Educational Technology, 46(2), 391-411.

[4] FitzPatrick, B., \& Schulz, H. (2015). Do Curriculum Outcomes and Assessment Activities in Science Encourage Higher Order Thinking?.Canadian Journal of Science, Mathematics and Technology Education, 15(2), 136-154.

[5] Mohammad, H., Fayyoumi, A., \& AlShathry, O. (2015). Do We Have to Prohibit the Use of Mobile Phones in Classrooms? International Journal of Interactive Mobile Technology, Vol. 9, Issue 2, 54-57. 
[6] Brierton, S., Wilson, E., Kistler, M., Flowers, J., \& Jones, D. (2016). A Comparison of Higher Order Thinking Skills Demonstrated in Synchronous and Asynchronous Online College Discussion Posts. NACTA Journal, 60(1), 14.

[7] Chinedu, C.C., Olabiyi, O.S., Kamin, T.B. (2015). Strategies for improving higher order thinking skills in teaching and learning of design and technology education. Journal of Technical Education and Training 7(2), 35-43.

[8] Dolan, E. L., \& Collins, J. P. (2015). We must teach more effectively: here are four ways to get started. Molecular biology of the cell, 26(12), 2151-2155.

[9] Han, I., \& Shin, W. S. (2016). The use of a mobile learning management system and academic achievement of online students. Computers \& Education, 102, 79-89.

[10] Nikou, S. A., \& Economides, A. A. (2016). The impact of paper-based, computer-based and mobile-based selfassessment on students' science motivation and achievement. Computers in Human Behavior, 55, 1241-1248.

[11] Fabian, K., Topping, K. J., \& Barron, I. G. (2016). Mobile technology and mathematics: effects on students' attitudes, engagement, and achievement.Journal of Computers in Education, 3(1), 77-104.

[12] Sulisworo, D., \& Toifur, M. (2016). The role of mobile learning on the learning environment shifting at high school in Indonesia. International Journal of Mobile Learning and Organisation, 10(3), 159-170.

[13] Hsia, J. W. (2016). The effects of locus of control on university students' mobile learning adoption. Journal of Computing in Higher Education, 28(1), 1-17.

[14] Spring, K. J., Graham, C. R., \& Hadlock, C. A. (2016). The current landscape of international blended learning. International Journal of Technology Enhanced Learning, 8(1), 84-102.

[15] Lai, C. L., Hwang, G. J., Liang, J. C., \& Tsai, C. C. (2016). Differences between mobile learning environmental preferences of high school teachers and students in Taiwan: a structural equation model analysis. Educational Technology Research and Development, 1-22.

[16] Pimmer, C., Mateescu, M., \& Gröhbiel, U. (2016). Mobile and ubiquitous learning in higher education settings. A systematic review of empirical studies.Computers in Human Behavior, 63, 490-501.

[17] Sulisworo, D., Ishafit, I., \& Firdausy, K. (2016). The Development of Mobile Learning Application using Jigsaw Technique. International Journal of Interactive Mobile Technologies (iJIM), 10(3), 11-16.

[18] Violante, M. G., \& Vezzetti, E. (2015). Virtual interactive e - learning application: An evaluation of the student satisfaction. Computer Applications in Engineering Education, 23(1), 72-91.

[19] Crawford, C. M., \& Smith, M. S. (2015). Rethinking Bloom's Taxonomy: Implicit Cognitive Vulnerability as an impetus towards higher order thinking skills.Exploring Implicit Cognition: Learning, Memory, and Social Cognitive Processes, 86-103.

[20] Heng, C.S., \& Ziguang, Y. (2015). Framework of Assessment for the Evaluation of Thinking Skills of Tertiary Level Students. Advances in Language and Literary Studies 6(5), 67-72.

[21] Saido, G. M., Siraj, S., Nordin, B., Bakar, A., \& Al Amedy, O. S. (2015). Higher Order Thinking Skills among Secondary School Students in Science Learning.Malaysian Online Journal of Educational Sciences, 3(3), 13-20.

[22] Zoller, U. (2015). Research-Based Transformative Science/STEM/STES/STESEP Education for "Sustainability Thinking": From Teaching to "Know" to Learning to "Think". Sustainability, 7(4), 4474-4491.

[23] Moore, B., Styron, J. \& Miller, K. (2015) Modeling Evidence-Based Application: Using Team-Based Learning to Increase Higher Order Thinking in Nursing Research. Systemics, Cybernetics and Informatics 13(3), 83-88.

[24] Project Management Institute. (2000). A guide to project management body of knowledge (PMBOK® guide), Newtown Square, PA. 